\title{
The role of $\mathrm{miR}-27 \mathrm{~b}-3 \mathrm{p} / \mathrm{HOXA10}$ axis in the pathogenesis of endometriosis
}

\author{
$\mathrm{Li} \mathrm{Li}^{1}$, Xiangcui Guo ${ }^{1}$, Juan Liu ${ }^{2}$, Beibei Chen ${ }^{1}$, Zhihui Gao ${ }^{1}$, Qianqing Wang ${ }^{1}$ \\ ${ }^{1}$ Department of Gynecology and Oncology, Xinxiang Central Hospital, Xinxiang, China; ${ }^{2}$ Department of Gynecology, the Third Affiliated Hospital \\ of Guangzhou Medical University, Guangzhou, China \\ Contributions: (I) Conception and design: L Li; (II) Administrative support: X Shi, X Guo; (III) Provision of study materials or patients: J Liu, B Chen; \\ (IV) Collection and assembly of data: All authors; (V) Data analysis and interpretation: Z Gao, Q Wang; (VI) Manuscript writing: All authors; (VII) \\ Final approval of manuscript: All authors. \\ Correspondence to: Qianqing Wang. Department of Gynecology and Oncology, Xinxiang Central Hospital, 56 Jinsui Avenue, Weibin District, \\ Xinxiang 453000, China. Email: wangq1111@126.com.
}

Background: To explore the effects of microRNA (miR)-27b-3p-mediated homeobox A10 (HOXA10) on the proliferation, migration, and invasion of endometriosis cells (hEM15A).

Methods: First, quantitative polymerase chain reaction (qPCR) was performed for the measurement of miR-27b-3p and HOXA10 expression in hEM15A cells and human embryonic stem cells (hESC). Then, the targeted relationship of miR-27b-3p with HOXA10 was verified by conducting a dual-luciferase reporter experiment. Subsequently, qPCR and western blot were performed to determine the effect of miR-27b$3 p$ on HOXA10 expression. Finally, Cell Counting Kit-8, Transwell, and scratch assays were employed to determine the effects of miR-27b-3p and HOXA10 on the proliferative, migratory, and invasive abilities of hEM15A cells.

Results: In hEM15A cells, miR-27b-3p expression was increased and showed a negative correlation with the expression of HOXA10 $(\mathrm{P}<0.05)$. The dual-luciferase reporter experiment confirmed that miR$27 \mathrm{~b}-3 \mathrm{p}$ targeted the HOXA10 gene. Furthermore, qPCR and western blotting showed that miR-27b-3p regulated the expression of HOXA10. The proliferation, migration, and invasion abilities of hEM15A cells was significantly inhibited by suppressing miR-27b-3p expression or overexpressing HOXA10 $(\mathrm{P}<0.05)$. Meanwhile, concurrent overexpression of miR-27b-3p and HOXA10 did not affect hEM15A cell activity $(\mathrm{P}>0.05)$.

Conclusions: Upregulation of miR-27b-3p can suppress HOXA10 expression, resulting in the enhancement of hEM15A cell proliferation, migration, and invasion.

Keywords: miR-27b-3p; HOXA10; endometriosis; proliferation; migration; invasion

Submitted Jan 13, 2021. Accepted for publication Mar 16, 2021.

doi: 10.21037/apm-21-343

View this article at: http://dx.doi.org/10.21037/apm-21-343

\section{Introduction}

Endometriosis is an estrogen-dependent condition in which glands and stroma of the endometrium develop ectopically, most commonly in the ovaries and peritoneal cavity (1). The causes of endometriosis are complex, but it is extremely common in clinical practice. Endometriosis affects $10-15 \%$ of women of childbearing age (2), and causes $20-50 \%$ of cases of infertility (3). It has been speculated that endometriosis may be related to genetic factors (4), but its pathogenesis is still not fully understood. Drug suppression of ovulation and surgery are not ideal treatments. Thus, efforts to illuminate the molecular mechanism underlying endometriosis and to find a non-invasive biomarker for the accurate diagnosis and treatment of the disease are urgently needed. 
MicroRNAs (miRNAs) function by binding to the untranslated region of messenger RNAs (mRNAs) to regulate gene expression or RNA degradation at the posttranscriptional level (5). It has been demonstrated that miRNAs can affect the development of many diseases via their effects on cell proliferation, apoptosis, invasion, and migration (6). Multiple studies have shown that the dysregulation of miRNAs is related to the pathogenesis of endometriosis, such as the dysregulation of inflammation, angiogenesis, tissue repair, and extracellular matrix formation (7). In fact, the role of some miRNAs in endometriosis has been reported. For example, the abnormal expression of miR-20a and miR-17-5p in endometriosis tissue and plasma are associated with estradiol signaling, hypoxia stress, and the promotion of angiogenesis (8). Furthermore, miR-200 has been reported to be related to the mesenchymal-epithelial transformation of the endometrial cells (9), while miR-199a has been shown to modulate the adhesion and infiltration of endometrial cells when upregulated, via the targeting of Chloride intracellular channel protein 4 (CLIC4), Reticulon 4 (RTN4), and Vinculin (VCL) (10). Finally, Liu et al. described miR-27b-3p to be a mediator of the development of endometrial cancer through its regulation of MARCH 2 (11); however, its role in endometriosis is still unknown.

Homeobox (HOX) proteins are highly conserved transcription factors. HOXA10, for instance, has been reported to be related to reproductive system diseases such as endometriosis (12), polycystic ovary syndrome (13), and hydrosalpinx (14). The deletion of the HOXA10 gene can also reduce the ability of fertilized eggs to implant in the endometrium (15). In adult women, endometrial stromal cells produce a considerably increased level of HOXA10 protein compared to glandular cells. Therefore, HOXA10 may play an extremely important guiding role in mesenchymal cell formation during the embryonic stage, as well as undifferentiated cell formation during adulthood. It has been shown that HOXA10 directly participates in intrauterine embryo formation and embryo implantation by regulating the downstream genes (16); however, how HOXA10 is regulated has not yet been fully studied. Accordingly, the present study set out to investigate the effects of miR-27b-3p on HOXA10, as well as the influence of the miR-27b-3p/HOXA10 axis on endometrial cell invasion and migration and its influence on embryo implantation. We present the following article in accordance with the MDAR reporting checklist (available at http://dx.doi.org/10.21037/apm-21-343).

\section{Methods}

\section{Material}

\section{Cell source and culture}

The human endometriosis cell line hEM15A (Cat. No.: AE-922) and human endometrial stromal cells (hESCs, Cat. No.: AE-887) were purchased from Shanghai Yubo Biotechnology Co., Ltd. hEM15A cells and hESCs were grown adherently in a medium containing $100 \mathrm{IU} / \mathrm{mL}$ penicillin, $50 \mathrm{mg} / \mathrm{mL}$ streptomycin, $2.5 \mu \mathrm{g} / \mathrm{mL}$ amphotericin $\mathrm{B}$, and $10 \%$ heat-inactivated fetal bovine serum at a temperature of $37{ }^{\circ} \mathrm{C}$, with $5 \% \mathrm{CO}_{2}$. Cells were continuously cultivated to the logarithmic growth period in preparation for subsequent experiments.

\section{Main reagents}

Trypsin, fetal bovine serum, incomplete culture medium, penicillin, streptomycin, amphotericin B, and Lipofectamine ${ }^{\mathrm{TM}} 2000$ Reagent were obtained from Invitrogen. We purchased Trizol and RNA extraction kits from Beijing Tianjian Biotechnology Co., Ltd. The SYBR Premix Ex Taq TM II Kit, PrimeScript ${ }^{\mathrm{TM}}$ RT reagent Kit, and miRNA PrimeScript ${ }^{\mathrm{TM}}$ RT Reagent Kit were bought from Takara (Dalian, China). Synthesis of the primers was performed by Sangon Biotech (Shanghai, China). Kits for the dual-luciferase reporter assay and protein extraction were obtained from Beijing Biolab Company and Nanjing KGI Biotech, respectively. Cell Counting Kit-8 (CCK8 ) and $\beta$-actin antibody were purchased from Shanghai Biyuntian Company, and Transwell chambers were purchased from Millipore.

\section{Study methods}

\section{Quantitative fluorescence polymerase chain reaction} Total RNA was extracted from hEM15A cells and hESCs using TRIzol and RNA extraction kits. After that, NanoDrop was used to measure the RNA quality and concentration. The RNA was then uniformly diluted to $500 \mathrm{ng} / \mu \mathrm{L}$. The PrimeScript RT and miRNA PrimescripTM RT kits were then used to reverse transcribe RNA into complementary DNA (cDNA). Then, with the SYBR Premix Ex Taq TM II kit serving as a template, quantitative polymerase chain reaction (qPCR) amplification was performed. Reverse transcription PCR was performed 
Table 1 Primer sequences

\begin{tabular}{lcc}
\hline Gene & Forward primer & Reverse primer \\
\hline miR-27b-3p & 5'-AGGGTTCACAGTGGCTAAG-3' & 5'-GAGAGGAGAGGAAGAGGGAA-3' \\
HOXA10 & 5'-AGGATTCCCTGGGCAATTC-3' & 5'-GACGCTGCGGCTAATCTCTA-3' \\
U6 & 5'-CTCGCTTCGGCAGCACA-3' & 5'-AACGCTTCACGAATTTGCGT-3' \\
GAPDH & 5'-AAGAAGGTGGTGAAGCAGGC-3' & 5'-TCCACCACCCTGTTGCTGTA-3' \\
\hline
\end{tabular}

on the LightCycle 96 fluorescent quantitative PCR machine (Roche, Switzerland). The specific steps were: predenaturation at $95{ }^{\circ} \mathrm{C}$ for 30 seconds, denaturation at $95{ }^{\circ} \mathrm{C}$ for 5 seconds, and annealing at $60^{\circ} \mathrm{C}$ followed by extension for 30 seconds for a total of 40 cycles. U6 and GAPDH were used for internal control, and the $2^{-\Delta \Delta \mathrm{Ct}}$ method was employed for the calculation of the relative mRNA expression level. Table 1 displays the primer sequences used, and the experiment was repeated 3 times.

\section{Cell transfection}

Logarithmic growth phase cells were harvested and diluted into a cell suspension, which was then inoculated in a 96well plate. Upon the cells reaching a density of $~ 70 \%$, Lipofectamine ${ }^{\mathrm{TM}} 2000$ was used to transfect cells with miR$27 \mathrm{~b}-3 \mathrm{p}$ inhibitor or miR-27-3p mimics. A control group was also established by transfecting cells with miR- Negative Control (NC). There were 3 replicates in each group. The transfection components were: $250 \mu \mathrm{L}$ Opti- Minimal Essential Medium (MEM) $+50 \mathrm{nmol} / \mathrm{L}$ mimics/inhibitor/ $\mathrm{NC}$ and $250 \mu \mathrm{L}$ Opti-MEM+5 $\mu \mathrm{L}$ Lipofectamine ${ }^{\mathrm{TM}} 2000$. After gentle and thorough mixing, the 2 solutions were settled at room temperature for 20 minutes, after which they were slowly added to a 96-well plate. The transfected cells were then collected for subsequent experiments.

\section{Targeting relationship verification by dual-luciferase reporter gene experiment}

The binding sites of miR-27b-3p and HOXA10 were predicted by TargetScan and miRanda online tools. Logarithmic growth phase cells were cultured in a 96well plate, and cells with a confluence of $80 \%$ were then transfected. After transfection, cells were continuously incubated for 48 hours, and the addition of $100 \mu \mathrm{L}$ of lysate was made to each of the wells. Following that, centrifugation was carried out, and a 96-well plate was used to collect the supernatant. After that the addition of $40 \mu \mathrm{L}$ of firefly luciferase substrate was made to each well, and following gentle mixing for 10 seconds, the fluorescence intensity was measured. For reference, $40 \mu \mathrm{L}$ of Renilla luciferase substrate was also added to the 96-well plate; then, the luciferase activity was measured with a Glomax luminometer (Promega, USA).

\section{Western blotting}

RIPA was used to separate proteins from cells. The same amounts of protein were then boiled together with the loading buffer at $95{ }^{\circ} \mathrm{C}$ for 10 minutes. Then, $20 \mu \mathrm{L}$ of the mixture (containing 30-50 $\mu \mathrm{g}$ of the sample) was separated by electrophoresis on $10 \%$ polyacrylamide gel. Transfer of the protein from the gel to a polyvinylidene difluoride (PVDF) membrane was carried out. The membrane was then subjected to blocking, followed by incubation with primary antibody overnight at $4{ }^{\circ} \mathrm{C}$. After a TBST wash, the membrane underwent incubation with the secondary antibody for 1 hour at room temperature. $\beta$-actin served as an internal reference. Image J was used for measurement of the gray value of the protein band. The experiment was performed 3 times.

\section{Cell viability detected by CCK-8}

After being seeded on a 96-well plate, cells were subjected to different treatments for 24 hours. Subsequently, the cells were subjected to incubation with $10 \%$ CCK- 8 solution at $37^{\circ} \mathrm{C}$ for 3 hours. Finally, a microplate reader was used to measure the absorbance $450 \mathrm{~nm}$.

\section{Scratch test}

Cells were uniformly prepared into a $600 \mu \mathrm{L}$ suspension and seeded on a 96-well plate. The cells were then spread over the bottom of the plate. A straight line was drawn in the middle of the plate using a $200 \mu \mathrm{L}$ pipette tip. Phosphatebuffered saline (PBS) was used to wash away any fallen cells before the addition of fresh medium. Pictures were then taken under a microscope, and cells were cultured in an incubator of constant temperature. After 24 hours and 

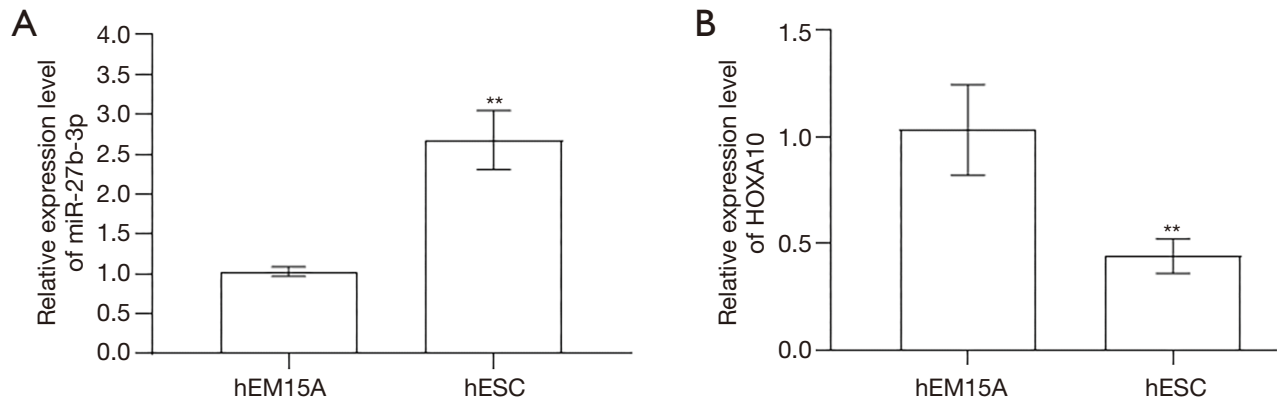

Figure 1 Relative expression of miR-27b-3p and HOXA10 in hEM15A cells and hESCs. **, P<0.01. HOXA10, homeobox A10; hEM15A, endometriosis cells; hESCs, human embryonic stem cells.

48 hours, pictures were taken again under the microscope. The remaining wound area was then determined through image processing, and Image $\mathrm{J}$ software from National Institutes of Health was used to determine the relative migration distance (migration distance $=$ initial distancefinal distance). The experiment was repeated 3 times.

\section{Transwell experiment}

Cells were inoculated into the upper layer of the Transwell chamber covered by Matrigel, with the regular medium at the bottom. The cells were cultured for 24 hours, following which, the chamber was taken out, and the cells were fixed with a mixture of formaldehyde and acetic acid for 15 minutes. After that, the cells were rinsed with PBS 3 times and those that had failed to pass through the chamber were wiped off with a cotton bud. After staining with crystal violet, cells were rinsed 3 times with PBS. The field of views was then randomly selected for imaging and the number of invaded cells was then counted.

\section{Statistical analysis}

GraphPad Prism 8 software was used to draw relevant statistical graphs. Statistical analyses were performed with SPSS 19.0 software (International Business Machines, Armonk, New York, USA). Student's $t$-test and one-way analysis of variance were employed for the analysis of between-group differences. $\mathrm{P}<0.05$ indicated a difference with statistical significance, $\mathrm{P}<0.01$ represented a extremely significant difference, and $\mathrm{P}<0.001$ represented a very significant difference.

\section{Results}

The expressions of miR-27b-3p and HOXA10 in bEM15A cells and bESCs was negatively correlated

For measurement of the expressions of miR-27b-3p and HOXA10 in hEM15A cells and hESCs, real-time fluorescent quantitative PCR was performed. It was found that the levels of miR-27b-3p showed a significant increase in hEM15A cells compared to hESC cells $(\mathrm{P}<0.05$, Figure $1 A$ ). Contrastingly, compared with that in hESC cells, the expression of HOXA10 in hEM15A cells showed a significant decrease $(\mathrm{P}<0.05$, Figure $1 B)$.

\section{miR-27b-3p bound to the HOXA10 gene in vitro}

The online tools TargetScan (http://www.targetscan.org) and miRanda (http://www.microrna.org) were used to predict and analyze the possible sites at which miR-27-3p may bind to HOXA10. The results showed that miR-27-3p and HOXA10 have targeted binding sites (Figure 2A). The prediction results were subsequently verified by performing the dual-luciferase report gene experiment. The results showed that after miR-27-3p mimics and WT-HOXA10 were co-transfected into hEM15A cells, the luciferase activity was significantly inhibited $(\mathrm{P}<0.05)$. Meanwhile, after miR-27-3p mimics and MUT-HOXA10 were cotransfected into hEM15A cells, the luciferase activity was 
A

HOXA10: 5' auuccUUUA - - UACUGUGAa 3'

$:|| \quad:|||||| \mid$

miR-27b-3p: 3' cgucuuGAAUCGGUGACACUu 5'

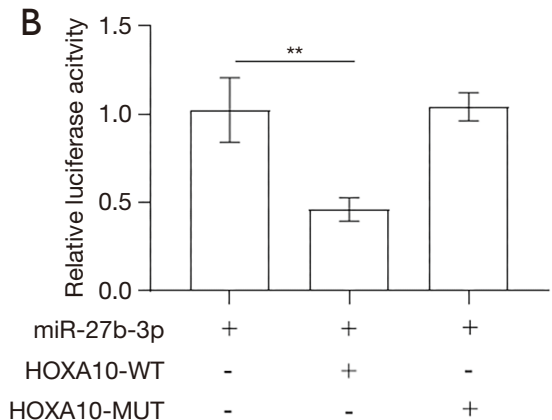

Figure 2 Dual-luciferase reporter gene experiment verifies miR-27b-3p targeting binding to HOXA10. **, P<0.01. Each treatment in the figure has '+' or '-', which means that with or without the corresponding treatment. HOXA10-WT, homeobox A10-wide type; HOXA10MUT, homeobox A10-mutant.

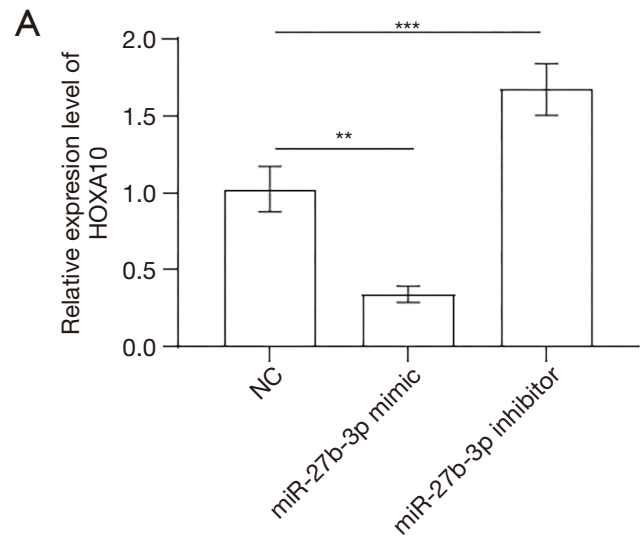

B

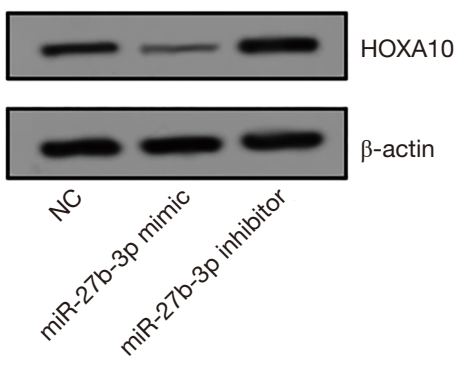

Figure 3 The effect of miR-27b-3p on the expressive levels of HOXA10 mRNA and protein in hEM15A cells. (A) HOXA10 mRNA expression level. (B) HOXA10 protein expression level. **, $\mathrm{P}<0.01$; ***, $\mathrm{P}<0.001$. HOXA10, homeobox A10; NC, negative control.

not significantly changed $(\mathrm{P}>0.05$, Figure $2 B)$.

\section{The effect of miR-27b-3p on HOXA10 expression}

Fluorescent quantitative PCR and western blotting were used to determine the effect of miR-27b-3p on the levels of HOXA10 expressed by hEM15A cells. Our findings revealed that compared with the control group, hEM15A cells overexpressing miR-27b-3p showed a significant reduction in HOXA10 at the mRNA and protein levels, whereas inhibiting miR-27b-3p expression significantly increased the mRNA and protein levels of HOXA10 (Figure 3A,B).

\section{miR-27b-3p downregulated HOXA10 to promote the} proliferation and invasion of bESCs in vitro

As shown in Figure 4A-C, inhibiting miR-27-3p expression was demonstrated to significantly inhibit the proliferation as well as reduce the invasion and migration ability of hEM15A cells in comparison with the controls $(\mathrm{P}<0.05)$. Overexpression of HOXA10 was also demonstrated to significantly inhibit the proliferation as well as reduce the invasion and migration ability of hEM15A cells in comparison with the controls $(\mathrm{P}<0.05)$. However, no significant effects on the proliferation of hEM15A cells were observed when miR-27-3p and HOXA10 were overexpressed concurrently (Figure 4A). 
A

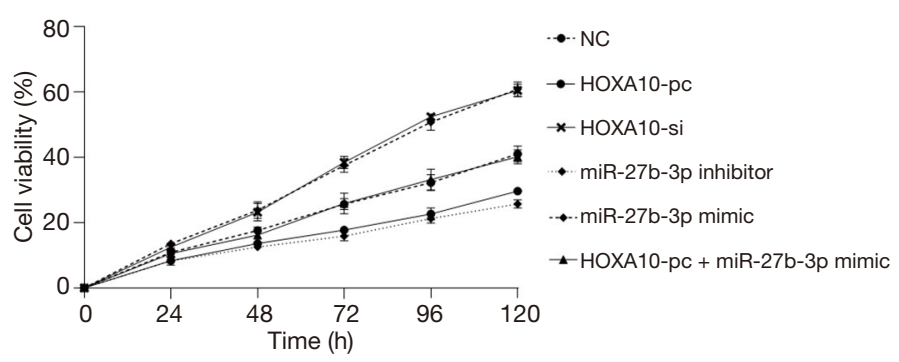

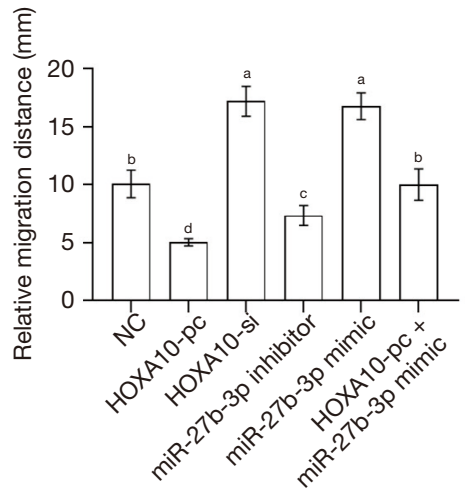

B
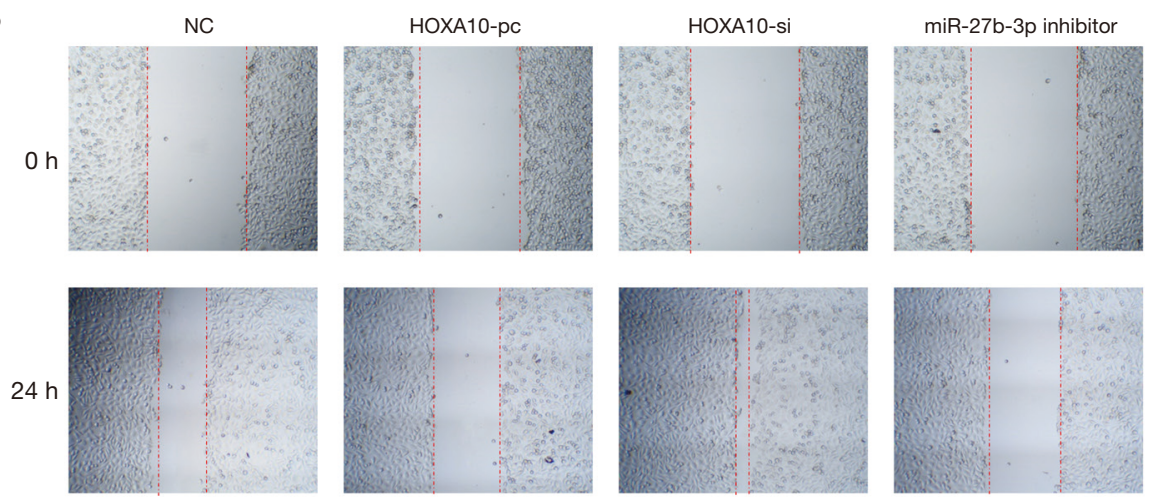

C
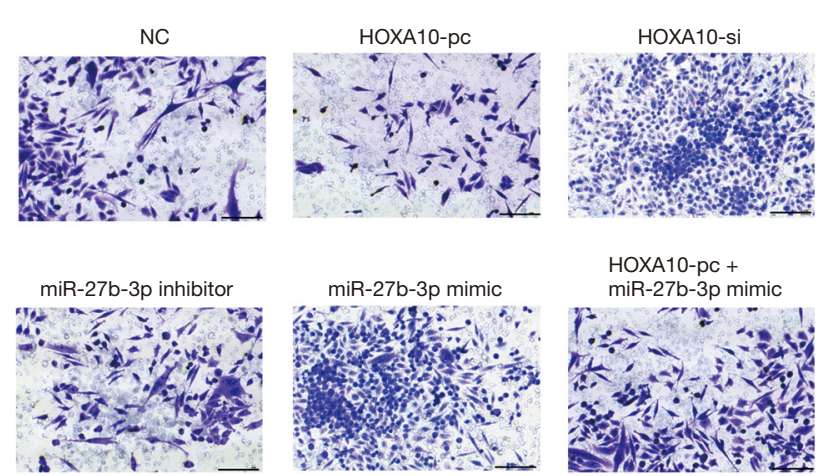
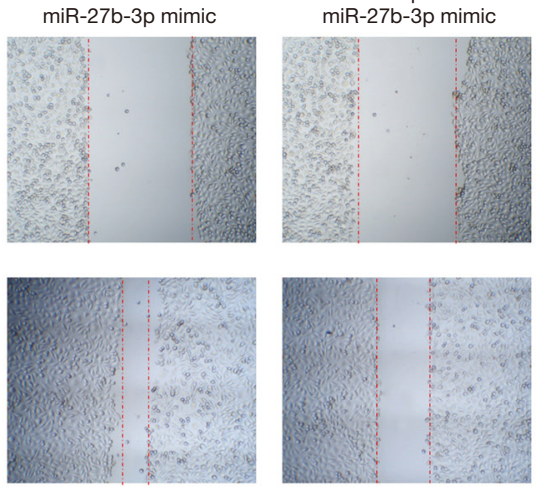

HOXA10-pc + miR-27b-3p mimic
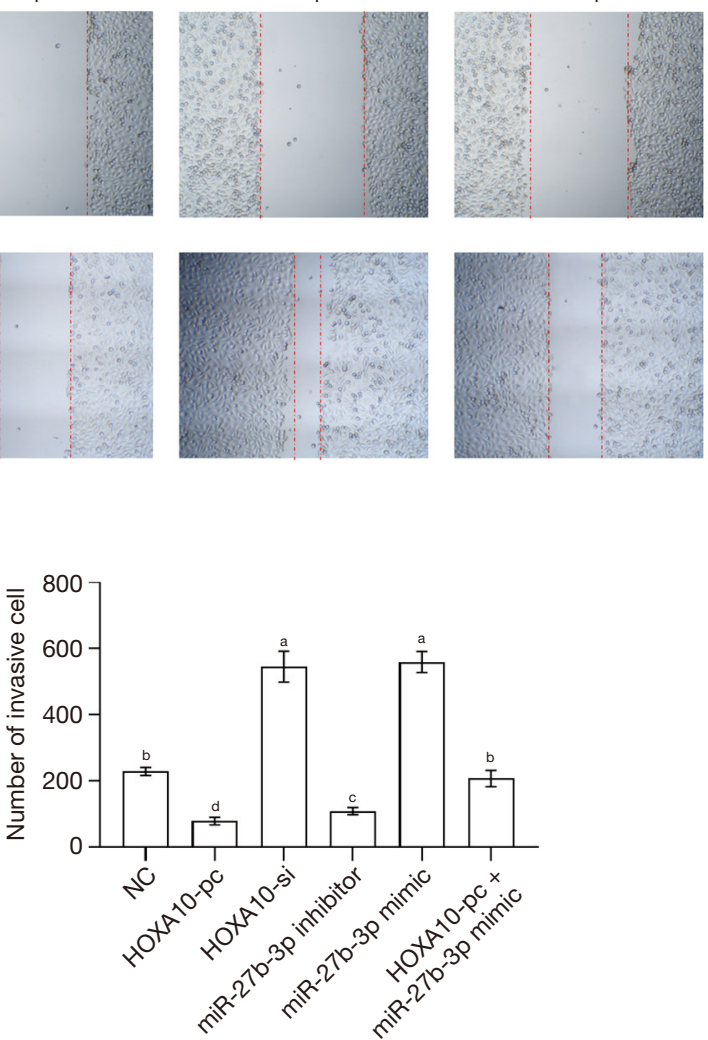

Figure 4 The effects of miR-27b-3p and HOXA10 on the proliferative, metastatic, and invasive abilities of hEM15A cells. (A) The effects of miR-27b-3p and HOXA10 on hEM15A cell proliferation. (B) The effects of miR-27b-3p and HOXA10 on hEM15A cell metastasis. (C) The effects of miR-27b-3p and HOXA10 on hEM15A cell invasion. Each treatment in the figure has different lowercase letters, which means that the difference between the different treatments is significant $(\mathrm{P}<0.05)$. ${ }^{\mathrm{a}} \mathrm{P}<0.05$ compared with other lowercase letters. ${ }^{b} \mathrm{P}<0.05$ compared with other lowercase letters. ${ }^{\mathrm{c}} \mathrm{P}<0.05$ compared with other lowercase letters. ${ }^{\mathrm{d}} \mathrm{P}<0.05$ compared with other lowercase letters. Bar $=100 \mu \mathrm{m}$. NC, negative control; HOXA10-pc, pcDNA3.1-homeobox A10 (overexpression); HOXA10-si, small interference RNA-homeobox A10 (inhibited expression). 


\section{Discussion}

At least $10 \%$ of women worldwide suffer from endometriosis, which can result in dysmenorrhea and infertility (17). However, the pathogenesis of the disease is still not fully understood, and there is no clinically effective treatment. Therefore, finding effective treatments for the condition is a major problem faced by researchers and doctors. The development of molecular biology and epigenetics has facilitated a deeper comprehension of the complex molecular mechanisms of endometriosis (18). As a type of non-coding RNA measuring only 20-24 nucleotides in length, miRNAs can regulate post-transcriptional gene expression or RNA degradation by interacting with the 3'-untranslated region of mRNAs, thus triggering the inhibition of translation (19). More and more evidence shows that miRNAs play a crucial regulatory role in the pathogenesis of many human diseases (20).

In this study, we found significant upregulation of miR27-3p in hEM15A cells in comparison to hESC cells, and inhibition of miR-27-3p expression could effectively reduce hEM15A proliferative and invasive abilities. The involvement of miR-27b-3p in cancers of the lung (21), thyroid (22), and breast (23), as well as in chronic liver injury (24), has been described previously. Therefore, endometriosis may also be related to the abnormal expression of miR-27-3p in endometrial cells.

The HOXA10 transcription factor is considered to be an important participant in the development of endometriosis (16). In this study, the expressive levels of HOXA10 were also determined in hEM15A cells and normal hESC cells. Our observation that the level of HOXA10 expression in hEM15A cells was significantly reduced was in accordance with those of earlier studie. HOXA10 has been reported to participate in the embryogenesis of uterine epithelium, stroma, and muscle (25). Its periodic expression is also found in the endometria of women as a response to steroid hormone use; thereby, it regulates the endometrium's ability to accept embryos (26). Some studies have shown that when HOXA10 was regulated in patients with endometriosis, the expression of HOXA10 in the ectopic endometrium of women with endometriosis could be restored, and the implantation ability of the embryo was also improved (27). It has also been confirmed that HOXA10 regulates embryo implantation by regulating the expression of the downstream gene EMX2 (28). Therefore, HOXA10 can be used as a molecular target for the treatment of endometriosis; however, the specific reasons for its decreased expression in endometriosis patients are still unclear.

The expressions of HOXA10 and miR-27-3p in hEM $15 \mathrm{~A}$ cells were negatively correlated, indicating that miR-27-3p may be involved in the regulation of the expression of HOXA10. The dual-luciferase reporter gene experiment confirmed our speculation that miR-27b-3p targets HOXA10 (Figure 2), and miR-27b-3p expression could also affect HOXA10 at the mRNA and protein levels in hEM15A cells (Figure 3). Both miR-27b-3p and HOXA10 were observed to individually regulate hEM15A cell proliferation, migration, and invasion. However, concurrent overexpression of miR-27b-3p and HOXA10 failed to affect the proliferative, migratory, or invasive ability of hEM15A cells, indicating that the expression of downstream HOXA10 is regulated by abnormal miR$27 \mathrm{~b}-3 \mathrm{p}$ expression, which thereby mediates the elevated proliferative, migratory, and invasive abilities of uterine hEM15A cells.

In conclusion, the results of the present research preliminarily show that the upregulation of miR-27b-3p can inhibit HOXA10 expression, thereby increasing hEM15A cell proliferation, migration, and invasion. The enhanced activity of hEM15A cells can promote the development of endometriosis, and can ultimately lead to dysmenorrhea and infertility in women with the condition. Therefore, miR-27b-3p combined with HOXA10 can be used as marker molecules for the early diagnosis and treatment of endometriosis. However, this study mainly focused on the cellular level and has certain limitations (For example, no animal model is constructed and verified in animal models). Therefore, in our future research, we will include animal experiments to verify the regulatory effects of miR-27b-3p and HOXA10 on the development of endometriosis in vivo.

\section{Acknowledgments}

Funding: None.

\section{Footnote}

Reporting Checklist: The authors have completed the MDAR checklist. Available at http://dx.doi.org/10.21037/apm-21343

Data Sharing Statement: Available at http://dx.doi. org/10.21037/apm-21-343 
Conflicts of Interest: All authors have completed the ICMJE uniform disclosure form (available at http://dx.doi. org/10.21037/apm-21-343). The authors have no conflicts of interest to declare.

Ethical Statement: The authors are accountable for all aspects of the work in ensuring that questions related to the accuracy or integrity of any part of the work are appropriately investigated and resolved.

Open Access Statement: This is an Open Access article distributed in accordance with the Creative Commons Attribution-NonCommercial-NoDerivs 4.0 International License (CC BY-NC-ND 4.0), which permits the noncommercial replication and distribution of the article with the strict proviso that no changes or edits are made and the original work is properly cited (including links to both the formal publication through the relevant DOI and the license). See: https://creativecommons.org/licenses/by-nc-nd/4.0/.

\section{References}

1. Bulun SE. Endometriosis. N Engl J Med 2009;360:268-79.

2. Herreros-Villanueva M, Chen CC, Tsai EM, et al. Endometriosis-associated ovarian cancer: What have we learned so far? Clin Chim Acta 2019;493:63-72.

3. Taylor RN, Yu J, Torres PB, et al. Mechanistic and therapeutic implications of angiogenesis in endometriosis. Reprod Sci 2009;16:140-6.

4. Koninckx PR, Ussia A, Adamyan L, et al. Pathogenesis of endometriosis: the genetic/epigenetic theory. Fertility Sterility 2019;111:327-40.

5. Pu M, Chen J, Tao Z, et al. Regulatory network of miRNA on its target: coordination between transcriptional and post-transcriptional regulation of gene expression. Cell Mol Life Sci 2019;76:441-51.

6. Huntzinger E, Izaurralde E. Gene silencing by microRNAs: contributions of translational repression and mRNA decay. Nat Rev Genetics 2011;12:99-110.

7. Teague EM, Print CG, Hull ML. The role of microRNAs in endometriosis and associated reproductive conditions. Hum Reprod Update 2010;16:142-65.

8. Ramón LA, Braza-Boïls A, Gilabert-Estellés J, et al. microRNAs expression in endometriosis and their relation to angiogenic factors. Hum Reprod 2011;26:1082-90.

9. Matsuzaki S, Darcha C. Epithelial to mesenchymal transition-like and mesenchymal to epithelial transitionlike processes might be involved in the pathogenesis of pelvic endometriosis. Hum Reprod 2012;27:712-21.

10. Wang WT, Zhao YN, Han BW, et al. Circulating microRNAs identified in a genome-wide serum microRNA expression analysis as noninvasive biomarkers for endometriosis. J Clin Endocrinol Metab 2013;98:281-9.

11. Liu L, Hu J, Yu T, et al. miR-27b-3p/MARCH7 regulates invasion and metastasis of endometrial cancer cells through Snail-mediated pathway. Acta Biochimica Et Biophysica Sinica 2019;51:492-500.

12. Kim JJ, Taylor HS, Lu Z, et al. Altered expression of HOXA10 in endometriosis: potential role in decidualization. Mol Hum Reprod 2007;13:323.

13. He H, Li T, Yin D, et al. HOXA10 expression is decreased by testosterone in luteinized granulosa cells in vitro. Mol Med Rep 2012;6:51.

14. Cakmak H, Taylor HS. Implantation failure: molecular mechanisms and clinical treatment. Hum Reprod Update 2011;17:242-53.

15. Ramathal CY, Bagchi IC, Taylor RN, et al. Endometrial decidualization: of mice and men. Sem Reproductive Med 2010;28:017-26.

16. Zanatta A, Rocha AM, Carvalho FM, et al. The role of the Hoxa10/HOXA10 gene in the etiology of endometriosis and its related infertility: a review. J Assist Reprod Genet 2010;27:701-10.

17. Eskenazi B, Warner ML. Epidemiology of endometriosis. Obstet Gynecol Clin North Am 1997;24:235-58.

18. Sapalidis K, Machairiotis N, Zarogoulidis P, et al. Genes' Interactions: A Major Contributor to the Malignant Transformation of Endometriosis. Int J Mol Sci 2019;20:1842.

19. Liang Z, Chen Y, Zhao Y, et al. miR-200c suppresses endometriosis by targeting MALAT1 in vitro and in vivo. Stem Cell Res Ther 2017;8:251.

20. Esteller M. Non-coding RNAs in human disease. Nat Rev Genetics 2011;12:861-74.

21. Sun $\mathrm{W}$, Zhang L, Yan R, et al. LncRNA promotes the proliferation, invasion, and migration of non-small cell lung cancer cells by targeting the/axis. Onco Targets Ther 2019;12:3945-54.

22. Xu Y, Han YF, Ye B, et al. miR-27b-3p is Involved in Doxorubicin Resistance of Human Anaplastic Thyroid Cancer Cells via Targeting Peroxisome ProliferatorActivated Receptor Gamma. Basic Clin Pharmacol Toxicol 2018;123:670-7.

23. Chen D, Si W, Shen J, et al. miR-27b-3p inhibits proliferation and potentially reverses multichemoresistance by targeting CBLB/GRB2 in breast 
cancer cells. Cell Death Dis 2018;9:188.

24. Li W, Chang N, Tian L, et al. miR-27b-3p, miR-181a$1-3 p$, and miR-326-5p are involved in the inhibition of macrophage activation in chronic liver injury. J Mol Med 2017;95:1091-105.

25. Taylor HS, Vanden Heuvel GB, Igarashi P. A conserved Hox axis in the mouse and human female reproductive system: late establishment and persistent adult expression of the Hoxa cluster genes. Biol Reprod 1997;57:1338-45.

26. Taylor HS, Arici A, Olive D, et al. HOXA10 is expressed in response to sex steroids at the time of implantation in

Cite this article as: Li L, Guo X, Liu J, Chen B, Gao Z, Wang Q. The role of miR-27b-3p/HOXA10 axis in the pathogenesis of endometriosis. Ann Palliat Med 2021;10(3):31623170. doi: 10.21037/apm-21-343 the human endometrium. J Clin Invest 1998;101:1379-84.

27. Taylor HS, Bagot C, Kardana A, et al. HOX gene expression is altered in the endometrium of women with endometriosis. Hum Reprod 1999;14:1328-31.

28. Zhu Y, Luo M, Huang H, et al. HOXA10, EMX2 and TENM1 expression in the mid-secretory endometrium of infertile women with a Müllerian duct anomaly. Reprod Biomed Online 2016;32:388-93.

(English Language Editor: J. Reynolds) 